\title{
Transições e duração do desemprego: uma revisão da literatura com novas evidências para Belo Horizonte
}

\author{
Mariangela Furlan Antigo \\ Cedeplar/UFMG \\ Ana Flávia Machado \\ Cedeplar/UFMG
}

\section{Palauras-chave}

desemprego, transição, modelos de sobrevivência.

Classificação JEL J64.

Key words

unemployment, mobility, survival models

JEL Classification J64.

\section{Resumo}

Este trabalho investiga os fluxos entre os estados do mercado de trabalho - ocupação, desemprego e inatividade - e a permanência no estado de desemprego na Região Metropolitana de Belo Horizonte, com base nos dados da PME, entre 1997 e 2001. Entre as características individuais, os resultados apontam que o comportamento do desemprego para jovens e mulheres é afetado muito mais pela maior incidência desses grupos nesse estado, porque são observadas maior intensidade e maior freqüência dos fluxos entre os outros estados de ocupação - desemprego e inatividade do que por um longo período de permanência no desemprego. No caso de longa duração, os indivíduos mais escolarizados que estão há mais tempo sem trabalho e que, na última ocupação, tinham carteira de trabalho assinada são os mais atingidos. Percebe-se que a seletividade do mercado de trabalho, as formas precárias de inserção e o comportamento da atividade econômica dessa região contribuem para o aumento tanto do desemprego quanto da rotatividade entre os grupos com menor estabilidade no mercado de trabalho. Nesse sentido, conclui-se que o fenômeno do desemprego na RMBH é afetado não só por fatores individuais, como também pelo comportamento da atividade econômica, confirmando, assim, o predito pelos modelos de busca de emprego.

\section{Abstract}

This work investigates movement between the states of the labor market - occupation, unemployment and inactivity - and the duration of unemployment in the Belo Horizonte Metropolitan Region, between 1997 and 2001, using panel data from IBGE's Monthly Employment Survey (PME). Among the individual characteristics, the results show that the behavior of unemployment for young people and women is much more affected by the bigher incidence of these groups in this state. This is so because greater intensity and longer stays are observed for these groups in the other two states, unemployment and inactivity, than by long periods of unemployment. Individuals with higher education levels who had signed labor contracts in their last jobs were the hardest hit by long-term unemployment. The selectiveness of the labor market, precarious labor relations and the behavior of economic activity in this region contribute to the increase in both unemployment and in turnover among groups with less stability in the labor market. The study concludes that the phenomenon of unemployment in the BH Metropolitan Area is affected not only by individual factors, but also by economic activity, thus confirming what the employment search models predicted. 


\section{1_Introdução}

O ambiente macroeconômico vivenciado pela economia brasileira na década de 1990 afetou intensamente o desempenho do mercado de trabalho. Uma das características mais marcantes observadas nesse período foi o aumento das taxas de desemprego, em que a evolução desfavorável é ainda agravada pela elevação simultânea da duração média do fenômeno, pelas fortes alterações ocorridas na sua composição, passando a atingir os mais diversos segmentos da força de trabalho. Outra característica das mudanças no mercado de trabalho brasileiro parece ter sido o aumento dos fluxos de entrada e saída da ocupação, desemprego e inatividade. Nesse sentido, a problemática do desemprego ganhou grande relevância nos anos 90 e tem ocupado lugar de destaque no debate econômico nacional.

As taxas mensais de desemprego no Brasil metropolitano permaneceram em níveis relativamente baixos do início da década de 90 até meados de 1997, quando passaram a apresentar leve tendência de crescimento, confirmada, a partir de 1998, em todas as regiões metropolitanas, como pode ser observado no gráfico a seguir. Contudo, a Região Metropolitana de Belo Horizonte ${ }^{1}$ apresenta um quadro mais alarmante, já que, de uma posição relativa com baixos níveis de desemprego, passa a figurar entre as regiões de níveis mais elevados (Gráfico 1).

Gráfico 1_ Taxa de Desemprego, Regiões Metropolitanas, 1991/2002

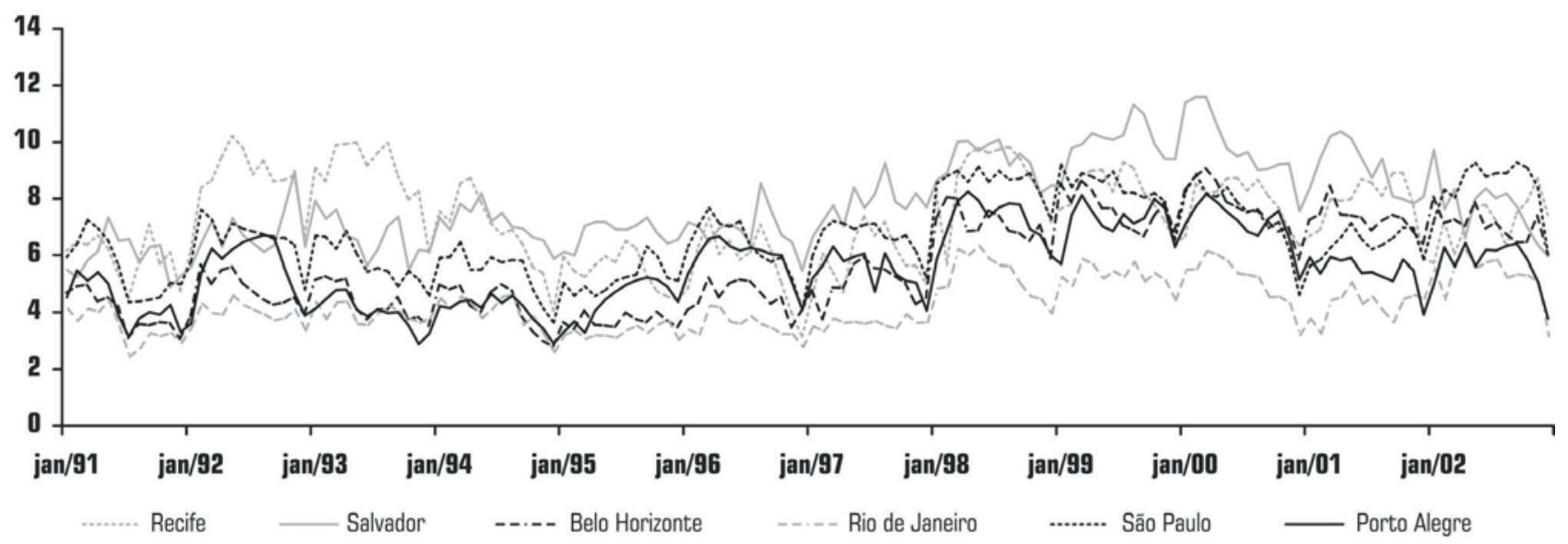

Fonte: IBGE, Pesquisa Mensal de Emprego, 1991/2002. 
Concomitantemente a esse panorama vislumbrado pela $\mathrm{RMBH}$, observouse, ao longo dos anos 90, nessa região, como retratado em Lemos (2004), um esgotamento de sua capacidade de crescimento sustentado e diferenciado, evidenciando, assim, uma perda de posição relativa no contexto econômico nacional.

Como fatores inibidores à sustentação do crescimento econômico dessa região, tem-se a precária situação atual de sua malha de transporte rodoviário interregional, que resulta em aumento do custo de transporte dos fluxos inter-regionais de bens e serviços e menor acessibilidade ao mercado nacional, a redução nas intenções de investimento, principalmente a partir do final da década e, sobretudo, o pequeno dinamismo recente da indústria metropolitana de Belo Horizonte. Tais dificuldades estruturais criam empecilhos para a retomada de um novo ciclo de expansão econômica (Lemos, 2004).

Esse reduzido dinamismo observado na indústria é dado pelo fato de Belo Horizonte se enquadrar como uma metrópole da segunda geração da industrialização brasileira, enquanto São Paulo e Rio de Janeiro compõem seu primeiro ciclo. Estas apresentam, por isso mesmo, uma estrutura diversificada, enquanto Belo Horizonte detém uma estrutura produtiva mais especializada, que talvez se reflita no desempenho e nas características do seu mercado de trabalho.

A estrutura produtiva especializada e o comportamento menos dinâmico dessa base contribuíram para o crescimento dos serviços tradicionais de baixa produtividade, para o aumento de ocupações informais (precários, temporários, conta própria) e o de indivíduos que não conseguem se inserir no mercado de trabalho. O setor terciário dessa região que, nos anos 70 e 80, foi caracterizado por uma modernização muito superior às demais regiões metropolitanas brasileiras, sofre interrupção dessa modernização na última década, fruto, principalmente, do refreamento da dinâmica industrial (Simões et al., 2004).

Tal contexto indica, assim, as dificuldades de aprofundar suas cadeias produtivas, bem como de diversificar sua estrutura industrial, o que afeta, de forma decisiva, a posição competitiva de Belo Horizonte no contexto nacional e internacional, refletindo-se diretamente no funcionamento do seu mercado de trabalho, em que os fenômenos do desemprego e da deterioração das condições de trabalho passaram a ocupar lugar de destaque entre os problemas enfrentados na região. O mercado de trabalho da $\mathrm{RMBH}$ parece apresentar características próprias dado o seu padrão de industrialização. 
Nesse sentido, é importante conhecer, na RMBH, os determinantes da duração do desemprego, bem como a composição dos fluxos de entrada e saída da força de trabalho da ocupação, desemprego e inatividade, ou seja, qualificá-lo e quantificá-lo em termos de seus principais atributos. A identificação das características do desemprego e o conhecimento de sua composição têm importantes implicações para a eficácia de políticas públicas que devem ser desenhadas de acordo com a sua estrutura.

O artigo está, portanto, dividido em seis seções, considerando esta introdução. $\mathrm{Na}$ próxima seção, mostra-se $\mathrm{o}$ modelo de busca por emprego que norteia toda a análise, apresentando-se, na terceira, algumas evidências de estudos internacionais e nacionais semelhantes. Na quarta e quinta seções são descritos a metodologia e os resultados obtidos, e, na última, traçam-se algumas considerações gerais sobre o trabalho.

\section{Modelo de busca por emprego}

Ao se considerar o fenômeno do desemprego, os modelos de busca por emprego apresentam grande relevância, tendo sido muito utilizados em estudos empíricos. Esses modelos consideram que o desemprego não é afetado somente pelo comportamento da atividade econômica, mas também por atributos pessoais daqueles que buscam uma ocupação. $\mathrm{Ou}$ seja, tais modelos procuram fornecer microfundamentos para o desemprego, enfatizando as condições de busca e as características pessoais do desempregado, na tentativa de explicar o desemprego.

De acordo com Layard, Nickell e Jackman (1991), o desemprego depende não apenas de pressões salariais, tais como as exercidas pelos sindicatos e/ou pela generosidade do sistema de benefícios, mas também da efetividade de busca do desempregado. Nessa efetividade de busca, são considerados quaisquer fatores que afetem a velocidade com a qual o desempregado encontra emprego, como a eficiência da transmissão de informação com relação a vagas, ao tempo e ao esforço dedicado pelo desempregado para buscar emprego, sua preferência com relação a vagas e empregos oferecidos e às práticas de recrutamento dos empregadores.

Os modelos de busca partem de uma função contratação em que o número de pessoas que deixam o desemprego por período (H) é em decorrência do número de vagas existentes na economia (V) e do número de indivíduos que efetivamente procurou emprego $(\mathrm{cU})$, sendo 
U o número de pessoas desempregadas, e c a efetividade média de busca. Assim, $H=b(V, c U)$.

A função contratação, H(.), é uma função linear homogênea de grau 1, em que o número de contratações dobra, se $\mathrm{V}$ e U fazem o mesmo. Dividindo-se ambos os lados por cU, tem-se:

$\frac{H}{U}=c h\left(\frac{V}{c U}, 1\right)$

Para a qual, a taxa de saída do desemprego depende apenas da razão de vagas com relação ao desemprego $\partial H / \partial V>0$ e da efetividade de busca dos desempregados $\partial H / \partial c U>0$.

Um indivíduo $i$, com efetividade $c_{i}$, terá a probabilidade de deixar o desemprego dado por sua efetividade de busca individual $c_{i}$ e pelas mesmas variáveis agregadas, isto é,

$\frac{h_{i}}{U}=c_{i} h\left(\frac{V}{c U}, 1\right)$

Assim, há dois conjuntos de fatores que afetam a obtenção de um posto de trabalho:

1. Os fatores individuais, os quais são funções do rendimento relativo e dos atributos pessoais, são dados por:
$c_{i}=c\left(\frac{B_{i}}{\mu_{w}}, q_{i}\right)$

em que $B i$ é a renda de reserva do indivíduo, e $\mu w$, o salário médio que o trabalhador espera ganhar, de forma que $B i / \mu w$ reflete uma medida de rendimento relativo. A variavel $q_{i}$ representa os atributos pessoais, como sexo, cor, idade, condição na família, experiência anterior, obtidos originalmente e ao longo do período de desemprego, que alteram a efetividade de se encontrar um emprego;

2. O grau de competição por vagas que reflete as variáveis agregadas macroeconômicas, ou seja, como o comportamento da atividade econômica afeta a obtenção de um posto de trabalho.

Nesse sentido, tem-se para o indivíduo que:

$h_{i}=c\left(\frac{B_{i}}{\mu_{w}}, q_{i}\right) b\left(\frac{V}{c U}, 1\right)$.

As equações $h_{i} / U=c_{i} h(V / c U, 1)$ e $h_{i}=c\left(B_{i} / \mu_{w}, q_{i}\right) b(V / c U, 1)$ introduzem uma forma funcional multiplicativa específica. Ou seja, uma mudança nas condições econômicas afeta as probabilidades de saída de todos os indivíduos do desem- 
prego em igual proporção. Um aumento de $10 \%$ no número de vagas, mantido mais constante, aumentará as chances de obter um emprego na mesma proporção.

O recurso à forma multiplicativa da função de contratação permite desagregar a taxa de desemprego de acordo com as características individuais e o comportamento macroeconômico da economia, de modo que os fatores individuais tendem a explicar a duração média do desemprego e os efeitos macroeconômicos, a incidência dos indivíduos no desemprego.

Nesse contexto, alguns autores partem da efetividade de busca para mostrar que certos grupos demográficos são mais discriminados no mercado de trabalho em detrimento de outros.

De acordo com Blanchard e Diamond (1994), as decisões de contratação das firmas, quando essas recebem propostas múltiplas aceitáveis de emprego, são feitas por "ranking" de candidatos ao emprego. Ou seja, as firmas contratam primeiro o trabalhador que se encontra desempregado há pouco tempo. Para tal, consideram que as decisões de contratação não atingem os trabalhadores contratados, mas determinam quais serão contratados, afetando, assim, a distribuição do desemprego. Desse modo, assumem que a duração do desemprego é utilizada como o único critério na contratação das firmas. $\mathrm{E}$ os desempregados de longo prazo estão menos propensos a ser contratados do que os de curto prazo, ou seja, o trabalhador que sobrevive mais tempo no desemprego tende a ficar mais estigmatizado, uma vez que as firmas tendem a não contratá-lo.

Com uma suposição alternativa, porém, com implicações equivalentes às encontradas por Blanchard e Diamond (1994), Pissarides (1992) assume que há deterioração das habilidades dos trabalhadores com a duração do desemprego, de forma que, enquanto os trabalhadores são "contratáveis", a firma prefere aqueles que estão desempregados por um tempo menor. Mediante um modelo de busca, tem-se que longa duração no desemprego desencoraja a abertura de novas vagas pelas firmas, dado que implica menor qualidade do pool de desempregados. A ocorrência de um choque negativo no emprego em um dado período reduz a contratação e, assim, prolonga a duração do desemprego, levando à perda de alguma qualificação dos trabalhadores desempregados e, por conseqüência, estes se tornam menos atraentes para as firmas, contribuindo para reduzir a oferta de postos de trabalho no próximo período e, conseqüentemente, ampliando a duração do desemprego. 
2 A denominação "análise de sobrevivência" originou-se na Medicina, em que o tempo de sobrevivência consiste no tempo médio de vida de determinado grupo de pacientes. Quando aplicada para estudos de desemprego, o tempo de sobrevivência consiste no tempo em que o indivíduo permanece no estado de desemprego.
Por sua vez, Montgomery (1991) considera o papel da estrutura social dada pelo padrão de vínculos sociais entre os indivíduos na determinação dos resultados do mercado de trabalho. Por meio de um modelo de seleção adversa, o autor mostra que os trabalhadores que estão bem conectados às informações referentes a vagas no mercado de trabalho podem se submeter às melhores vagas que os deficientemente conectados. Assim, aqueles que se encontram no estado de desemprego há muito tempo perdem tanto a capacidade de se manter atualizado sobre tais informações quanto a possibilidade de encontrar vagas de melhor qualidade do que os demais.

\section{3_ Evidências empíricas}

No que tange aos fluxos de entrada e saída no mercado de trabalho, um instrumental utilizado é a matriz de transição, que, como o próprio nome diz, mensura as probabilidades de transição entre os estados. No que diz respeito à duração do desemprego, um dos métodos mais utilizados é a análise de sobrevivência, ${ }^{2}$ por meio dos métodos não paramétricos e dos modelos semiparamétricos e paramétricos.

As transições no mercado de trabalho tendem a atingir com mais intensidade alguns grupos de trabalhadores.
Entre as características consideradas, merece destaque o sexo e a idade dos indivíduos. Ao se considerar o sexo, diferenças substanciais nas estimativas das probabilidades de transição são encontradas por Bivar (1993), que, entre as probabilidades consideradas, constata que as responsáveis pelo diferencial nas taxas de desemprego de homens e mulheres são a maior probabilidade de mudança da ocupação para a inatividade, para as mulheres, e, para os homens, a maior probabilidade de obter uma ocupação. Contudo, quando considerado o gênero apenas dos jovens, Clark e Summers (1990b) verificam pequena diferença nessas probabilidades.

Além disso, a partir das probabilidades de transição, uma nova estimativa das taxas de desemprego e de participação na força de trabalho realizada por Bivar (1993) mostra que as taxas de desemprego são mais sensíveis às mudanças nas probabilidades de transição da ocupação para o desemprego e do desemprego para a ocupação, e que a taxa de participação é mais sensível à probabilidade de realizar entrada bem-sucedida no mercado de trabalho. Tais resultados levam à idéia de segmentação do mercado de trabalho por gênero.

No que concerne à idade, Clark e Summers (1990b) encontram diferenças 
notáveis entre as probabilidades de transição dos jovens que estão na escola e fora dela, brancos e não-brancos e entre jovens e adultos. A freqüência e a intensidade de movimentos entre os estados de desemprego e inatividade evidenciados neste estudo apontam, segundo os autores, para uma difícil distinção entre ambos, indicando, assim, dúvida em distinguir o desemprego e a inatividade para as pessoas jovens. Isso corrobora uma conclusão mais geral encontrada em um estudo anterior desses autores. ${ }^{3}$

Confirmando os resultados encontrados para o comportamento dos jovens, Flori (2003) mostra que, estando em qualquer um dos três estados do mercado de trabalho em $t$, o adulto sempre apresenta maior probabilidade de estar ocupado em $t+1$ comparado ao jovem, e o jovem de se encontrar desempregado ou inativo do que o adulto. Comparativamente, os adultos passam mais tempo ocupados do que os jovens, e estes, por sua vez, passam mais tempo no desemprego e na inatividade do que os adultos, resultando em uma taxa de desemprego muito maior para os jovens do que para os adultos. ${ }^{4}$ Além disso, a autora mostra que, com as probabilidades de transição de ocupação do adulto, o jovem aumenta sensivelmente seu tempo na ocupação e diminui o tempo no desemprego e na inatividade, ao passo que o adulto, com as probabilidades do jovem, tende a aumentar seu tempo no desemprego e na inatividade e a reduzir seu tempo na ocupação. Assim sendo, conclui que o comportamento da transição da ocupação para os três estados do mercado de trabalho é fator determinante da alta ou da baixa taxa de desemprego tanto para jovens quanto para adultos.

Concernente aos estudos que tratam a duração do desemprego, busca-se constatar, considerando tanto as evidências internacionais como para o Brasil, se existe relação entre os atributos pessoais e a duração do desemprego e se as questões macroeconômicas são relevantes para explicar a duração. Os autores utilizam, em sua quase totalidade, o instrumental dos métodos não paramétricos e dos modelos semiparamétricos e paramétricos para mensurar a duração do desemprego, bem como variáveis que podem afetar esse tempo.

A duração média estimada do desemprego varia entre os autores, dependendo do período e da região considerada. Roed, Raaum e Goldstein (1999) constatam para a Noruega, em outubro de 1990, 6.3 meses de desemprego, em média. Galiani e Hopenhayn (2000), para a Argentina, ${ }^{5}$ no período de 1989-1998, verificam uma duração média de 7.4 me- $\cdots \cdots \cdots \ldots$

3 Clark e Summers

(1990a). "Labor market

dynamics and unemployment:

a reconsideration".

4 A taxa de desemprego de estado estacionário encontrada foi de 13,5 e 5,1\% para jovens e adultos, respectivamente. Já a taxa de desemprego observada na PME foi de 13,8\% para os jovens e de 5,1\% para os adultos. As taxas de desemprego efetiva e calculada são muito próximas, indicando, assim, que a hipótese forte de Markov não cria viés nos resultados.

5 Os autores utilizam dados para Buenos Aires, visto (dado) que esse mercado de trabalho cobre, aproximadamente, metade da força de trabalho do país. 


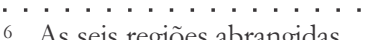
6 As seis regiões abrangidas pela Pesquisa Mensal de Emprego são: São Paulo, Belo Horizonte, Rio de Janeiro, Porto Alegre, Salvador e Recife. ses. Em relação às evidências para o caso brasileiro, para a Região Metropolitana de São Paulo, Bivar (1993) verifica uma duração média do desemprego de 6,2 meses, para o período de 1983 a 1990 , Menezes-Filho e Picchetti (2000), 6,64 meses, para o ano de 1997, e Avelino (2001), 4,25 meses, para o período entre 1984 e 1997. Para o ano de 1999, Penido e Machado (2003a) apuram duração média estimada de, aproximadamente, 10 meses, nas seis regiões metropolitanas pesquisadas da $\mathrm{PME}^{6}$ no ano de 1999. E, por fim, uma duração do desemprego de 6,76 meses é constatada por Penido e Machado (2003b) na RMBH, no ano de 1999.

As características dos indivíduos guardam forte relação com o tempo de permanência nesse estado. As mulheres, por exemplo, apresentam menor probabilidade de encontrar uma ocupação do que os homens (Foley, 1997; Roed, Raaum e Goldstein, 1999; Galiani e Hopenhayn, 2000; Weber e Hofer, 2004; Bivar (1993); Menezes-Filho e Picchetti, 2002; Avelino, 2001; Oliveira, 2002; Malbouisson e Menezes, 2004).

Os chefes de família apresentam menor duração do desemprego do que os não-chefes (Menezes-Filho e Picchetti, 2000 e 2002; Avelino, 2001; Malbouisson e Menezes; 2004), e, de acordo com Penido e Machado (2003a), os filhos possu- em menor probabilidade de encontrar um novo posto de trabalho. Além disso, a idade contribui para aumentar a duração do desemprego, e, assim, os indivíduos mais velhos tendem a permanecer mais tempo no estado de desemprego do que os mais jovens (Nickell, 1979; Foley, 1997; Lancaster, 1979; Chuang, 1999; Roed, Raaum e Goldstein, 1999; Weber e Hofer, 2004; Menezes-Filho e Picchetti, 2000 e 2002; Oliveira, 2002). Por outro lado, Malbouisson e Menezes (2004) constatam que a duração média de acordo com a idade é praticamente a mesma para os grupos considerados.

Com relação aos anos de estudo, quanto maior a escolaridade dos indivíduos, maior a duração do desemprego (Roed, Raaum e Goldstein, 1999; Menezes-Filho e Picchetti, 2000 e 2002; Avelino, 2001; Penido e Machado, 2003a e b; Oliveira, 2002; Malbouisson e Menezes, 2004). Mas, para Foley (1997), a duração do desemprego não se altera quando comparados os níveis de educação diferenciados e, de acordo com Galiani e Hopenhayn (2000), a escolaridade possui um efeito não monotônico na duração e, às vezes, ambíguo.

Somando-se aos atributos pessoais, de acordo com as características do último posto de trabalho do indivíduo, verifica-se maior probabilidade de encontrar 
uma ocupação para os indivíduos que trabalharam anteriormente na construção civil (Avelino, 2001; Penido e Machado, 2003a) e no comércio (Penido e Machado, 2003a). Por sua vez, os indivíduos que se empregaram anteriormente no setor de serviços, quando comparados aos que se empregaram na indústria, possuem menor probabilidade de encontrar um novo posto de trabalho (Penido e Machado, 2003a). Além disso, maior duração é verificada para aqueles que possuíam emprego no setor formal (Menezes-Filho e Picchetti, 2000).

É constatado, também, que o tempo de trabalho na última ocupação contribui para aumentar a duração do desemprego, visto que, quanto maior o tempo trabalhado na ocupação anterior, maior a probabilidade de permanecer no estado de desemprego (Avelino, 2001; Menezes-Filho e Picchetti, 2000 e 2002). Relativo ao tempo de não-trabalho, aqueles há mais tempo sem trabalho apresentam menor taxa de saída do estado de desemprego para a ocupação (Penido e Machado, 2003a e 2003b).

Ademais, pessoas demitidas da última ocupação têm maior duração no estado de desemprego relativa àquelas que saíram voluntariamente (Foley, 1997; Menezes-Filho e Picchetti, 2000 e 2002). A posse de carteira assinada na ocupa- ção anterior aumenta o tempo de permanência no desemprego (Menezes-Filho e Picchetti, 2002; Avelino, 2001), bem como o recebimento de FGTS (MenezesFilho e Picchetti, 2002; Penido e Machado, 2003a). Somando-se a isso, no que tange aos benefícios recebidos na última ocupação, maior duração do desemprego é verificada para aqueles que apresentam maior razão de substituição, medida por Nickell (1979) como a relação benefícios/renda recebida na última ocupação e por Lancaster (1979) como a razão entre benefícios do desemprego e renda obtida na última ocupação vezes um fator, dependendo da duração do desemprego decorrida. Roed, Raaum e Goldstein (1999) verificam um efeito positivo dos benefícios do seguro desemprego na duração desse estado, e Weber e Hofer (2004) retratam que o acesso a benefícios e assistência aumenta a sua duração.

Por fim, é verificado que indivíduos com experiência de trabalho anterior apresentam menor duração do desemprego (Menezes-Filho e Picchetti, 2000 e 2002; Avelino, 2001) e indivíduos que esperam receber salários maiores e que utilizam agências governamentais para busca de um emprego possuem menor probabilidade de sair do estado de desemprego (Chuang, 1999).

Além dos atributos pessoais e de características do último posto de trabalho, 
alguns autores levam em consideração informações que refletem as condições conjunturais do ambiente econômico que o desempregado encontra no momento em que começa a procurar uma ocupação, na tentativa de mensurar se as questões macroeconômicas são relevantes para explicar a duração do desemprego. Nickell (1979) e Foley (1997) constatam que as condições de demanda do mercado de trabalho local medidas pela razão vaga/ desemprego apresentam efeito significativo na duração do desemprego, uma vez que menor razão vaga/desemprego leva a maior permanência no estado de desemprego. Roed, Raaum e Goldstein (1999) e Foley (1997) verificam que indivíduos de regiões com maiores taxas de desemprego apresentam maiores períodos de permanência nesse estado, e Menezes-Filho e Picchetti (2002) apontam importantes diferenças na relação entre desemprego regional e a duração do desemprego. Alto desemprego na época em que o indivíduo perde a ocupação tende a aumentar a duração do desemprego na Região Metropolitana de Porto Alegre e Recife e a reduzir a duração nas Regiões Metropolitanas de São Paulo, Belo Horizonte, Rio de Janeiro e Salvador.

Como pode ser observado, a maior parte dos estudos relatados com relação ao desemprego, em nível internacional e para o caso do Brasil, apresenta algumas semelhanças. De forma geral, pôde-se constatar que as mulheres, os indivíduos mais velhos, com nível educacional mais elevado, que foram demitidos da última ocupação, com maior tempo de trabalho, que receberam FGTS na última ocupação, aqueles há mais tempo sem trabalhar e aqueles que recebem benefícios apresentam maior duração do desemprego, ao passo que os chefes de família, os casados e os indivíduos com experiência de trabalho anterior tendem a apresentar maior probabilidade de encontrar um posto de trabalho.

Em que pese à vasta literatura sobre o tema, a sua dimensão deletéria sobre a sociedade requer que ainda haja maior investimento em pesquisa e formulação de políticas públicas. Sendo assim, o intuito deste trabalho, em uma região metropolitana específica, é:

_ identificar as características daqueles mais sujeitos às transições que envolvem a condição de desempregado;

_ identificar as características daqueles mais envolvidos em maior permanência no desemprego;

_ contrapor atributos pessoais e condições macroeconômicas na determinação da duração do desemprego. 


\section{4_Metodologia}

\section{1_Matrizes de probabilidades de transição}

A metodologia adotada para analisar a dinâmica entre os três estados do mercado de trabalho - ocupação, desemprego e inatividade - utiliza como referencial o trabalho de Clark e Summers (1990c), no qual se assume que o comportamento individual pode ser caracterizado por uma matriz de probabilidades de transição $p^{i}$, dada por:

$p^{i}=\left[\begin{array}{ccc}p_{o o}^{i} & p_{o n}^{i} & p_{o n}^{i} \\ p_{u o}^{i} & p_{u n}^{i} & p_{u n}^{i} \\ p_{n o}^{i} & p_{n u}^{i} & p_{n n}^{i}\end{array}\right]$

em que $p_{j k}^{i}$ representa a probabilidade de o indivíduo i estar no estado $k$ no período $t+1$, condicionado ao fato de ele se encontrar no estado $j$ em $t$. É possível calcular, da matriz de probabilidade de transição $p^{i}$, a proporção do tempo alocado em cada estado do mercado de trabalho por cada indivíduo $i$. Considerando $\pi_{j}^{i}$ como a fração de tempo que o indivíduo $i$ aloca para o estado $j$, tem-se que:

$\pi_{j}^{i}=\left[\begin{array}{c}\pi_{o}^{i} \\ \pi_{u}^{i} \\ \pi_{n}^{i}\end{array}\right]$
Dado que $\pi_{j}^{i}$ não é uma variável observável, considera-se a suposição de que as transições entre os estados do mercado de trabalho são tratadas como um processo de Markov, no qual o desenvolvimento futuro do processo, posto que o indivíduo se encontra em um estado, depende apenas desse estado, e não de como se chegou a ele. O uso de matrizes de transição de Markov envolve, assim, a suposição que as decisões de transição dos indivíduos não dependem do tempo que eles permanecem em determinado estado.

Logo, o Teorema Básico das Cadeias de Markov postula que qualquer sistema caracterizado por tal matriz alcançará um estado estacionário que é independente de condições iniciais, e a proporção de estado estacionário em cada estado deve ser encontrada como uma função da matriz de transição inteira. A relação entre $\pi_{t}^{i} \mathrm{e} \pi_{t-1}^{i}$ pode ser escrita na forma matricial como: $\pi_{t}^{i}=p_{t}^{\prime} \pi_{t-1}^{i}$. Em estado estacionário, $\pi_{t}^{i}=\pi_{t-1}^{i}$, de forma que $\pi_{t}^{i}=p_{t}^{\prime} \pi_{t}^{i}$.

Utilizando a condição de estado estacionário e o fato de as probabilidades de transição entre os estados serem independentes do tempo que o indivíduo permanece em um estado particular, tem-se que: 


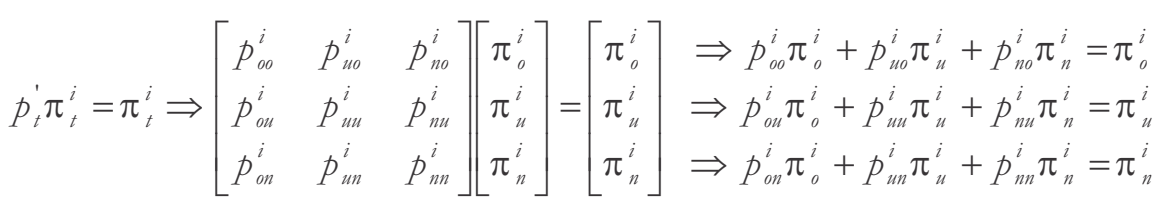

Qualquer equação do sistema linear acima é linearmente dependente das outras. Contudo, pode-se utilizar a propriedade segundo a qual $\pi_{o}^{i}+\pi_{u}^{i}+\pi_{n}^{i}=1$, substituí-la em qualquer uma das equações e, por esse processo, resolver o sistema.

A taxa de desemprego é dada por:

$$
\frac{\pi_{u}}{\pi_{u}+\pi_{o}} \text {. }
$$

A distribuição no estado estacionário da população $(\mathrm{N})$ nos estados do mercado de trabalho pode ser encontrada pelas probabilidades médias individuais. Isto é:

$\Pi_{j}=\frac{1}{N} \sum_{i=1}^{N} \Pi_{j}^{i}$

de forma que

$\frac{\Pi_{u}}{\prod_{u}+\Pi_{o}}$

caracteriza a taxa de desemprego agregada.

A principal crítica em tratar as matrizes de transição como um processo de Markov é a dependência das probabilida- des de transição entre os estados e a duração em cada um. Essa crítica tende a ser mais acentuada no que tange ao estado de desemprego, dado que, quanto mais tempo o indivíduo se encontra nesse estado, menor será a probabilidade de saída dele para uma ocupação. Já está evidenciado que pessoas que permanecem por mais tempo nessa situação apresentam, em média, menor propensão a se encontrarem ocupadas do que aquelas desempregadas por período menor. Neste caso, a hipótese adotada é muito forte e reduz a precisão das estimativas, gerando resultados enviesados. Para verificar se o uso dessa hipótese reduz a precisão dos resultados, comparam-se as taxas de desemprego do estado estacionário com as de desemprego observadas na Pesquisa Mensal de Emprego. Se as duas taxas são próximas, pode-se inferir que os resultados obtidos não são enviesados.

O conhecimento dos fatores determinantes dos fluxos no mercado de trabalho se torna crucial para o entendimento da composição do desemprego e, assim, de seus fatores discriminatórios. 


\section{2_ Análise de sobrevivência}

Para estimar a duração do desemprego e a taxa de saída do indivíduo desempregado para a condição de ocupado, utiliza-se como referencial a análise de sobrevivência retratada em Colosimo (2001).

Esta análise admite que o tempo de falha, ou seja, a duração observada da transição de um estado para outro, é uma variável aleatória não negativa $T$, que é usualmente especificada pela sua função sobrevivência ou pela função risco (ou taxa de falha). A função sobrevivência $S(t)$ é definida como a probabilidade de determinado indivíduo sobreviver ao tempo $t$, e, em termos probabilísticos, é escrita como $S(t)=P(T \geq t)$; a função risco $h(t)$ indica a probabilidade de a falha ocorrer em um intervalo de tempo $\left(t_{1}+t_{2}\right)$ e pode ser expressa em termos da função sobrevivência como $S\left(t_{1}\right)-S\left(t_{2}\right)$. Essa função pode ser definida como a probabilidade de a falha ocorrer no intervalo $\left(t_{1}+t_{2}\right)$, dado que não ocorreu antes de $t_{1}$, dividida pelo comprimento do intervalo. Pode, assim, ser expressa por

$\frac{S\left(t_{1}\right)-S\left(t_{2}\right)}{\left(t_{2}-t_{1}\right) S\left(t_{1}\right)}$

Redefinindo o intervalo como $(t, t+\Delta t)$, tem-se que:
$h(t)=\frac{S(t)-S(t+\Delta t)}{\Delta t S(t)}$.

Com $\Delta t$ bem pequeno, $h(t)$ representa a taxa de falha instantânea no tempo $t$ condicional à sobrevivência até $\mathrm{o}$ tempo $t$. Portanto,

$h(t)=\lim _{\Delta t \rightarrow 0} \frac{P(t \leq T<t+\Delta t / T \geq t)}{\Delta t}$

Ou seja, quando $\Delta t$ tende a zero, a função risco indica o limite da razão entre a probabilidade de ocorrência do evento entre $t$ e $\Delta t$, posto que o indivíduo sobreviveu ao tempo $T$ e à variação do tempo.

Nesse contexto, a variável dependente considerada é o tempo transcorrido até a ocorrência da falha, ou seja, até a saída do estado de desemprego para a entrada no estado de ocupado. Entretanto, a informação referente a esse tempo não é exata, uma vez que alguns indivíduos que estão desempregados durante o período da pesquisa não encontram uma ocupação antes de o estudo terminar, de forma que se sabe que o desemprego dessas pessoas durou, no mínimo, o que foi observado na amostra, mas não se tem condições de precisar o tempo. Tais informações são ditas censuradas à direita. Todos os métodos de estimação de funções risco e sobrevivência as utilizam, 
Os métodos não paramétricos são importantes para descrever os dados de sobrevivência pela sua simplicidade e facilidade de aplicação, posto que exigem apenas a variável tempo de duração do desemprego. A principal característica deste método é dada pela não-exigência de uma especificação da função risco. Entretanto, inviabiliza uma análise mais elaborada que permita a inclusão de co-variadas na análise. Nos resultados, informa-se, por limitação do tamanho do artigo, apenas a duração média. ao invés de descartá-las da amostra; porém as tratam de forma diferenciada das informações que não estão censuradas.

Após o reconhecimento do evento de interesse (encontrar um posto de trabalho) e dos indivíduos censurados, pode-se estimar a função sobrevivência, que fornece a probabilidade do indivíduo continuar desempregado no período $t$, e a função risco, que indica a probabilidade de o desemprego terminar em dado período, tendo em vista que ele já durou até aquela data.

Essas funções podem ser obtidas valendo-se dos métodos não paramétri$\cos ^{7}$ e dos modelos semiparamétricos e paramétricos. Os modelos paramétricos são mais eficientes, todavia menos flexíveis do que os modelos semiparamétricos. Além das variáveis utilizadas nestes últimos, é necessária a especificação de uma distribuição de probabilidade para o tempo de falha na função de risco.

Entre as distribuições de probabilidade que podem ser assumidas neste tipo de análise, destacam-se as distribuições exponencial, de Weibull, log-normal e a gama generalizada. Tais distribuições são historicamente conhecidas por sua adequação às situações respostas de tempo até a ocorrência do evento considerado. A distribuição exponencial apresenta uma função risco constante, e a de Wei- bull se caracteriza por ser monótona, ou seja, crescente, decrescente ou constante. A função risco da distribuição log-normal, por sua vez, não apresenta forma específica, crescendo a partir da origem até atingir um valor máximo e decrescendo a partir de então. Por sua vez, a distribuição gama generalizada assume uma variedade imensa de formas.

Das distribuições de probabilidade citadas, destaca-se a gamma generalizada por apresentar uma função risco flexível, a qual permite várias inclinações e inclui as distribuições de Weibull, exponencial e log-normal como casos especiais.

Uma vez especificada a distribuição de probabilidade e supondo que $\theta$ represente o vetor de parâmetros dos dados e que a densidade da duração de $t$ seja dada por $f(t ; \theta)$, a função de verossimilhança para $\theta$ será dada por:

$$
L(\theta)=\prod_{i=1}^{n} f\left(t_{i} ; \theta\right)
$$

As observações são divididas em dois grupos, em que as $r$ primeiras são as não censuradas $(1,2, \ldots r)$ e as $n-r$ seguintes são as censuradas $(\mathrm{r}+1, \mathrm{r}+2, \ldots n)$. A função de verossimilhança assume, assim, a seguinte forma:

$$
L(\theta)=\prod_{i=1}^{r} f\left(t_{i} ; \theta\right) \prod_{i=r+1}^{n} S\left(t_{i} ; \theta\right)
$$


A maximização dessa função gera as estimativas dos coeficientes e do parâmetro de duração.

\section{3_ Fonte de dados e variáveis selecionadas}

A fonte de dados empregada neste trabalho é a Pesquisa Mensal de Emprego (PME) do Instituto Brasileiro de Geografia e Estatística (IBGE). Trata-se de um inquérito domiciliar realizado mensalmente para seis regiões metropolitanas do Brasil (São Paulo, Rio de Janeiro, Porto Alegre, Belo Horizonte, Recife e Salvador), na forma de um painel rotativo. A natureza da informação longitudinal, ainda que de painel rotativo, possibilita a aplicação de modelos de análise de sobrevivência. Os indivíduos em um domicílio são entrevistados por quatro meses, saem da amostra por oito meses e retornam por mais quatro meses no ano subseqüente, quando são excluídos definitivamente da amostra.

A PME é utilizada para a construção de dois bancos de dados em que um deles é destinado para o cálculo das probabilidades de transição dos indivíduos nos três estados do mercado de trabalho e possíveis simulações, ao passo que o outro banco é utilizado para a análise de sobrevivência dos indivíduos no desem- prego no mesmo período. Os dados da PME são informações individuais que podem ser divididas em qualitativas e quantitativas. As variáveis qualitativas se referem a sexo, condição na família, ramo de atividade anterior, posição na ocupação anterior, posse de carteira assinada, se era remunerado na ocupação anterior, recebimento de FGTS, motivo pelo qual entrou no estado de desemprego e providência tomada para encontrar emprego. Já as variáveis quantitativas são: idade, nível de escolaridade, tempo de procura, tempo no último emprego e tempo de não-trabalho.

O primeiro banco é formado valendo-se das duas primeiras entrevistas mensais dos indivíduos, no intuito de captar sua transição no mercado de trabalho de um mês para o outro. É importante ressaltar que a análise das probabilidades de transição é realizada em cada dimensão isoladamente, de forma que, com base nos resultados obtidos, torna-se possível comparar diversos aspectos dos indivíduos, como homens e mulheres, jovens, adultos e idosos. O período considerado para a construção desse banco estendeu-se de outubro de 1997 a setembro de 2000 e foi assim definido por possibilitar maior número de observações disponíveis para os mesmos indivíduos. 
$\because \cdots \cdot \cdot \cdot \cdot$

8 Embora variáveis como faturamento na indústria, utilização da capacidade instalada, indicador de desempenho do comércio varejista e produto interno bruto, entre outras, devessem ser consideradas na análise para melhor retrato dos aspectos macroeconômicos da $\mathrm{RMBH}$, essas infelizmente não puderam ser consideradas, em razão da indisponibilidade desses dados em periodicidade mensal para a metrópole de Belo Horizonte.
Selecionaram-se, ainda, pessoas com idade entre 18 e 65 anos. Para o primeiro período (1997/1998), foram apreciadas 24.484 observações e, para o período subseqüente, 26.221 observações. Na amostra total, em média, 46\% são homens. A idade média da amostra pesquisada é de 37 anos com um desvio-padrão da ordem de 1,3, e a média de anos de estudo dos indivíduos é de sete anos com desvio de 4,2.

Para a análise de sobrevivência, o segundo banco é formado apenas pelos indivíduos que se declararam desempregados na primeira entrevista e que se encontram na faixa etária entre 18 e 65 anos. Nesse banco, consideram-se as oito entrevistas dos indivíduos, e o período estende-se de outubro de 1997 a setembro de 2001. A amostra é formada por 794 observações em que $67 \%$ são homens e $42 \%$ são chefes de família. A média de idade é de 31 anos, e a amostra apresenta média de 8 anos de estudo. No que concerne à última ocupação, em média, 21\% são provenientes da indústria, $54 \%$ eram empregados com carteira de trabalho assinada, $20 \%$ pediram para sair da última ocupação, 64\% consultaram empregadores para obter um posto de trabalho e $97 \%$ possuem experiência de trabalho anterior.

A variável duração do desemprego considera o período de procura por trabalho reportado pelo entrevistado mais os meses das oito entrevistas da amostra, em que o indivíduo declarou-se sem ocupação e à procura desta. Outra variável foi construída: a variável tempo sem trabalho, por meio da informação individual de período sem trabalho registrado na PME. Todas as duas variáveis podem apresentar o viés decorrente de erro de memória dos entrevistados, na medida em que consideram informações retrospectivas. Assim como em outros trabalhos, não é feita correção para esse viés. A variável duração do desemprego, além de apresentar censura à esquerda, como já descrito, apresenta censura intervalar, uma vez que se supõe que, nos oito meses em que não é entrevistado, o indivíduo permanece no mesmo estado relatado no último mês da primeira remessa (quarto mês da amostra deste trabalho). O procedimento foi o mesmo de Avelino (2001).

Além dos dados disponíveis na PME, nesta análise é utilizada uma dummy temporal, para mensurar os efeitos do comportamento econômico na duração do desemprego. São considerados dois biênios - 1998/1999 e 2000/ 2001 -, no intuito de verificar se há um efeito de período sobre a duração do desemprego na RMBH. ${ }^{8}$ 


\section{5_Resultados}

\section{1_Matrizes de probabilidades de transição}

Analisam-se, a seguir, os resultados do modelo de transição entre os três estados no mercado de trabalho (ocupação, desemprego e inatividade) segundo sexo, idade e escolaridade.

\subsubsection{Sexо}

A população feminina possui taxa de participação na força de trabalho historicamente menor do que a da masculina. Embora a participação da mulher na força de trabalho tenha aumentado, a taxa de atividade masculina ainda é superior.
Assim sendo, há maior probabilidade de encontrar homens na condição de ocupação, e mulheres na inatividade.

As probabilidades de transição dos indivíduos, total e por sexo, podem ser visualizadas na Tabela 1.

De forma geral, é possível notar probabilidade elevada de um indivíduo permanecer no mesmo estado do mercado de trabalho nos dois períodos em questão, com exceção apenas para aqueles que, em $t$, se encontram desempregados. Para estes últimos, as probabilidades de transição para os três estados apresentam-se bem significativas, ainda que a de continuar desempregado seja maior.

Tabela 1 - Probabilidades de transição total e por sexo, para a RMBH, no período de 1997 a 2000

\begin{tabular}{|c|c|c|c|c|c|c|c|}
\hline & \multicolumn{2}{|c|}{$\begin{array}{c}\text { Ocupados } \\
(t+1)\end{array}$} & \multicolumn{2}{|c|}{$\begin{array}{l}\text { Desempregados } \\
\qquad(t+1)\end{array}$} & \multicolumn{2}{|c|}{$\begin{array}{l}\text { Inativos } \\
(t+1)\end{array}$} \\
\hline & & $97 / 98$ & $99 / 00$ & $97 / 98$ & 99/00 & $97 / 98$ & $99 / 00$ \\
\hline \multirow{3}{*}{ Ocupados $(t)$} & Total & 91.38 & 91.01 & 2.09 & 2.34 & 6.52 & 6.65 \\
\hline & Homens & 92.99 & 92.54 & 2.46 & 2.75 & 4.55 & 4.71 \\
\hline & Mulheres & 89.00 & 88.92 & 1.56 & 1.78 & 9.45 & 9.29 \\
\hline \multirow{3}{*}{ Desempregados $(t)$} & Total & 28.13 & 27.77 & 43.84 & 42.98 & 28.03 & 29.25 \\
\hline & Homens & 33.79 & 36.07 & 47.27 & 44.14 & 18.95 & 19.79 \\
\hline & Mulheres & 21.86 & 19.15 & 40.04 & 41.77 & 38.10 & 39.08 \\
\hline \multirow{3}{*}{ Inativos $(t)$} & Total & 8.58 & 8.93 & 2.99 & 3.85 & 88.43 & 87.22 \\
\hline & Homens & 12.59 & 13.30 & 4.56 & 5.48 & 82.84 & 81.21 \\
\hline & Mulheres & 7.05 & 7.07 & 2.40 & 3.15 & 90.56 & 89.78 \\
\hline
\end{tabular}

Fonte: Elaboração própria com base nos microdados da PME de 1997, 1998, 1999 e 2000. 
9 A PME capta a condição de ocupação na semana de referência; assim sendo, parcela dos que se declaram sem trabalho e sem procura de trabalho são considerados inativos.
As mulheres, estando ocupadas ou desempregadas em $t$, apresentam maior probabilidade de transitar para a inatividade no período seguinte, bem como de permanecer na inatividade em $t+1$, encontrando-se inativas no período $t$.

Ao se encontrarem desempregados em $t$, os homens apresentam maior probabilidade de permanecer na força de trabalho, em razão da maior possibilidade de obter um posto de trabalho em $t+1$ e pela probabilidade muito menor de desistir de procurar uma ocupação e sair do mercado de trabalho. Além disso, é importante salientar que, no grupo dos desempregados, as mulheres possuem uma transição para a inatividade significativamente superior à dos homens, ficando próxima às probabilidades observadas de permanência no desemprego. De maneira geral, os resultados indicam menor estabilidade do sexo feminino e a presença de alta rotatividade entre os estados do mercado de trabalho para as mulheres.

Quando a análise se estende no tempo, a probabilidade de os indivíduos ocupados, desempregados e inativos, tanto totais como segmentados por sexo, transitarem para outro estado ou ainda permanecerem no mesmo estado é con- firmada. Embora as evidências apontem queda na probabilidade dos desempregados permanecerem nesse estado por causa do aumento na inatividade, o resultado pode estar relacionado ao desalento, ${ }^{9}$ e não propriamente à inatividade, visto que o ano de 1999 é marcado por mudanças políticas e econômicas no País, que geraram um ambiente de grande incerteza em relação à economia. Isso afeta o comportamento dos indivíduos na busca por uma ocupação, que, diante das dificuldades, se tornam desencorajados, declarando a não-procura. Em função disso, pode estar ocorrendo uma transferência do número de desempregados para a inatividade, e não de fato uma redução no desemprego.

A Tabela 2 registra as estimativas, para homens e mulheres, das frações de tempo em cada estado do mercado de trabalho - ocupação, desemprego e inatividade - e suas respectivas taxas de desemprego de estado estacionário (taxa de desemprego calculada) e observadas na PME (taxas de desemprego efetivas) no período de 1999/2000. As estimativas para o período de 1997/1998 e para as demais características foram realizadas, e os resultados foram os esperados. 
Tabela 2_Fração de tempo em cada estado do mercado de trabalho e taxas de desemprego, calculada e efetiva, segundo o sexo, para a RMBH, no período de 1999/2000

\begin{tabular}{|c|c|c|c|c|c|}
\hline \multirow[b]{2}{*}{ Categoria } & \multicolumn{3}{|c|}{ Fração de Tempo (\%) } & \multicolumn{2}{|c|}{ Таха de Desemprego } \\
\hline & Ocupação & Desemprego & Inatividade & Calculada & Efetiva' \\
\hline Homens & 70,20 & 5,78 & 24,02 & 7,61 & 7,55 \\
\hline Mulheres & 41,54 & 4,18 & 54,28 & 9,14 & 8,95 \\
\hline
\end{tabular}

Fonte: Elaboração própria com base nos microdados da PME de 1999 e 2000.

Nota: (1) Para o cáculo da taxa de desemprego observada na PME, considera-se a segunda entrevista de cada indivíduo, do respectivo período considerado.

Os homens, na maior parte do tempo, estão ocupados, ao passo que as mulheres passam mais tempo na inatividade. Na condição de desemprego, os homens se sobressaem, em relação às mulheres; dessa forma permanecem um tempo muito mais expressivo na força de trabalho do que o sexo oposto.

As diferenças comportamentais entre homens e mulheres resultam principalmente dos distintos papéis que eles desempenham no lar. O comportamento da força de trabalho feminina é mais errático do que o masculino, posto que a entrada e a permanência da mulher no mercado de trabalho ainda é associada à atividade do chefe do domicílio. Embora o papel que as mulheres desempenham historicamente no lar esteja passando por significativas alterações oriundas das mudanças demográficas e do mercado de trabalho, há, ainda, maior irregularidade na inserção. A decisão de trabalhar ou não das mulheres tende ainda a responder principalmente a fatores econômicos como inovação nas oportunidades de ocupação dos maridos ou variação em seus salários.

A taxa de desemprego de estado estacionário é de 7,61 e 9,14\%, respectivamente, para homens e mulheres. A taxa de desemprego efetiva, a qual leva em consideração o número de pessoas desempregadas e ocupadas da PME, foi de 7,55\% para os homens e de 8,95\% para as mulheres. As taxas de desemprego efetiva e calculada são muito próximas, e, assim, pode-se inferir que a hipótese forte de Markov $^{10}$ considerada não tende a enviesar os resultados.

\subsection{2_ Idade}

As decisões de oferta de trabalho dos indivíduos são feitas continuamente ao longo do ciclo de vida ativa da população, e a alocação do tempo no mercado de trabalho é feita em diferentes direções nos diversos estágios do ciclo de vida. A taxa de partici-
10 A hipótese forte de Markov admite que as probabilidades de transição entre os três estados do mercado de trabalho não dependem do tempo que os indivíduos estão em determinado estado. 
pação relativa à idade apresenta padrão semelhante a um U-invertido, em que a participação no mercado de trabalho aumenta conforme a idade dos indivíduos até determinado ponto, quando se atinge o auge da vida produtiva. A partir desse ponto, a saída do mercado de trabalho começa a ser significativa, principalmente nos anos próximos à aposentadoria. Nesse sentido, as taxas de participação tendem a ser menores para trabalhadores jovens, maiores para trabalhadores no auge do ciclo de vida ativo, e também menores para trabalhadores mais velhos. Espera-se, assim, que a inatividade entre os jovens e os mais idosos se apresente de forma mais acentuada do que para os indivíduos no auge do ciclo de vida ativo.

A Tabela 3 retrata as probabilidades de transição, de acordo com a idade dos indivíduos, para a região metropolitana. É possível observar uma tendência diferenciada, dependendo do período do ciclo de vida ativo em que o indivíduo se encontra.

Tabela 3_ Probabilidades de transição segundo grupos de idade, para a RMBH, no período de 1997 a 2000

\begin{tabular}{|c|c|c|c|c|c|c|c|}
\hline & \multirow[t]{2}{*}{ Idade } & \multicolumn{2}{|c|}{$\begin{array}{l}\text { Ocupados } \\
(t+1)\end{array}$} & \multicolumn{2}{|c|}{$\begin{array}{l}\text { Desempregados } \\
\qquad(t+1)\end{array}$} & \multicolumn{2}{|c|}{$\begin{array}{c}\text { Inativos } \\
(t+1)\end{array}$} \\
\hline & & $97 / 98$ & 99/00 & $97 / 98$ & 99/00 & $97 / 98$ & $99 / 00$ \\
\hline \multirow{4}{*}{ Ocupados $(t)$} & 18 a 24 & 89.88 & 89.43 & 3.84 & 4.03 & 6.28 & 6.54 \\
\hline & 25 a 30 & 91.05 & 92.38 & 3.21 & 2.89 & 5.74 & 4.74 \\
\hline & 31 a 50 & 93.72 & 93.17 & 1.56 & 1.93 & 4.72 & 4.90 \\
\hline & 50 a 65 & 88.61 & 87.43 & 1.03 & 1.40 & 10.36 & 11.17 \\
\hline \multirow{4}{*}{ Desempregados $(t)$} & 18 a 24 & 25.30 & 24.71 & 45.43 & 45.18 & 29.27 & 30.12 \\
\hline & 25 a 30 & 34.74 & 28.68 & 47.37 & 48.90 & 17.89 & 22.43 \\
\hline & 31 a 50 & 28.57 & 32.20 & 45.48 & 41.27 & 25.95 & 26.53 \\
\hline & 50 a 65 & 29.69 & 27.27 & 28.13 & 34.09 & 42.19 & 38.64 \\
\hline \multirow{4}{*}{ Inativos $(t)$} & 18 a 24 & 13.76 & 14.55 & 9.51 & 12.90 & 76.73 & 72.55 \\
\hline & 25 a 30 & 8.51 & 12.35 & 6.70 & 8.50 & 84.79 & 79.15 \\
\hline & 31 a 50 & 12.07 & 12.29 & 3.29 & 4.86 & 84.63 & 82.84 \\
\hline & 50 a 65 & 7.96 & 8.74 & 0.85 & 1.34 & 91.19 & 89.92 \\
\hline
\end{tabular}

Fonte: Elaboração própria com base nos microdados da PME de 1997, 1998, 1999 e 2000. 
Entre os mais jovens, com idade entre 18 e 24 anos, que se encontram ocupados no período $t$, há maior probabilidade de saída da força de trabalho do que de permanência na procura de uma ocupação. Quando desempregados em $t$, a probabilidade de saírem da força de trabalho torna-se mais significativa ainda, alcançando em média $30 \%$, contra probabilidades, em média, de 45 e $25 \%$ de permanecerem no desemprego e encontrarem uma ocupação, respectivamente. Por sua vez, quando inativos, apresentam probabilidade em torno de $75 \%$ de permanecerem no mesmo estado em $t+1$.

Por sua vez, os indivíduos no auge de seu ciclo de vida ativo (aqueles com idade entre 31 e 50 anos) apresentam probabilidades mais favoráveis que os jovens quando ocupados em $t$, graças à maior probabilidade de se manterem ocupados em $t+1$ e menor probabilidade de se encontrarem desempregados ou inativos.
E, por fim, no que concerne aos mais idosos, a probabilidade de se tornarem inativos no período subseqüente é muito mais elevada do que para os demais, independentemente do estado em que esses se encontram no período $t$.

Os resultados retratados aqui corroboram estudos anteriores como o de Clark e Summers (1990b), que evidenciam que a maior parte dos fluxos para o emprego dos jovens é dada por aqueles que se encontram na inatividade, e que grande parte dos jovens que deixam um emprego tende a sair da força de trabalho. Somando-se a este, Flori (2003) aponta resultados semelhantes no que tange à saída da força de trabalho pelos mais jovens para todas as regiões metropolitanas no ano de 2001.

As estimativas das frações de tempo de cada faixa etária nos três estados, bem como as taxas de desemprego geradas, para o período de 1999/2000, são ilustradas abaixo (Tabela 4).

Tabela 4_ Fração de tempo em cada estado do mercado de trabalho e taxas de desemprego, calculada e efetiva, segundo grupos de idade, para a RMBH, no período de 1999/2000

\begin{tabular}{|c|c|c|c|c|c|}
\hline \multirow[b]{2}{*}{ Categoria } & \multicolumn{3}{|c|}{ Fração de Tempo (\%) } & \multicolumn{2}{|c|}{ Tаха de Desemprego } \\
\hline & Ocupação & Desemprego & Inatividade & Calculada & Efetiva \\
\hline 18 a 24 anos & 62,41 & 10,90 & 26,69 & 14,87 & 15,56 \\
\hline 25 a 30 anos & 68,88 & 7,91 & 23,21 & 10,31 & 10,23 \\
\hline 31 a 50 anos & 68,89 & 4,45 & 26,66 & 6,07 & 5,75 \\
\hline 51 a 65 anos & 40,88 & 1,88 & 57,24 & 4,39 & 4,31 \\
\hline
\end{tabular}

Fonte: Elaboração própria com base nos microdados da PME de 1999 e 2000. 
Os indivíduos mais jovens (18 a 24 anos) encontram-se mais tempo desempregados do que os demais, passando um pouco mais de $60 \%$ de seu tempo ocupados e em torno de $25 \%$ na inatividade. Esses resultados geram taxa de desemprego de $14,87 \%$, a maior taxa se comparada às demais. Os indivíduos com idade entre 31 e 50 anos, ou seja, aqueles que tendem a permanecer no mercado de trabalho de forma mais estável, apresentam taxa de desemprego bem menor do que a dos jovens, ficando mais tempo ocupados e, conseqüentemente, menos tempo no estado de desemprego. Por fim, os mais idosos passam a maior parte do tempo na inatividade, e as frações de tempo na ocupação e no desemprego apresentam-se em menor magnitude, gerando, assim, a taxa de desemprego mais baixa, na ordem de 4,39\%. É importante destacar, mais uma vez, que as taxas de desemprego calculadas e efetivas são bem próximas.

\subsection{3_Anos de estudo}

Pessoas com mais escolaridade tendem a permanecer em uma ocupação com maior facilidade, principalmente no mercado de trabalho urbano, como é o caso da região metropolitana. Assim sendo, espera-se maior probabilidade de permanência na ocupação, ou seja, menos transição entre as três condições para aqueles que detêm maior escolarização.
Estando ocupados no período $t$, a probabilidade de continuar nesse estado em $t+1$ é crescente com os anos de estudo, e de transitar para o desemprego ou para a inatividade decresce à medida que a escolaridade aumenta.

De forma geral, o comportamento das probabilidades de transição se mantém no tempo, com algumas exceções que apresentam variações de grande magnitude, principalmente entre aqueles que se encontram desempregados no período $t$, que figuram como sem instrução e com mais de 11 anos de estudo. Quando são considerados os dois períodos, os analfabetos apresentam redução de grande magnitude na probabilidade de encontrar uma ocupação e probabilidade muito maior de se encontrar na inatividade.

Essa grande variação pode estar relacionada ao contexto macroeconômico que marcou o ano de 1999. É acentuado o aumento da probabilidade de esses se encontrarem na inatividade quando se compara ao período anterior. Contudo, vale ressaltar que talvez não seja um aumento da inatividade em sentido estrito, mas, sim, do desemprego pelo desalento, que, diante da dificuldade de serem absorvidos pelo mercado, os menos educados tenderam a transitar para a inatividade. 
Tabela 5_ Probabilidades de transição segundo os anos de escolaridade, para a RMBH, no período de 1997 a 2000

\begin{tabular}{|c|c|c|c|c|c|c|c|}
\hline & \multirow{2}{*}{$\begin{array}{l}\text { Anos } \\
\text { de Estudo }\end{array}$} & \multicolumn{2}{|c|}{$\begin{array}{l}\text { Ocupados } \\
(t+1)\end{array}$} & \multicolumn{2}{|c|}{$\begin{array}{c}\text { Desempregados } \\
\qquad(t+1)\end{array}$} & \multicolumn{2}{|c|}{$\begin{array}{c}\text { Inativos } \\
(t+1)\end{array}$} \\
\hline & & $97 / 98$ & 99/00 & $97 / 98$ & 99/00 & $97 / 98$ & $99 / 00$ \\
\hline \multirow{6}{*}{ Ocupados $(t)$} & 0 & 86.60 & 83.83 & 2.13 & 3.00 & 11.28 & 13.16 \\
\hline & 1 a 3 & 87.30 & 86.25 & 2.85 & 3.13 & 9.85 & 10.62 \\
\hline & 4 a 7 & 89.91 & 88.98 & 2.45 & 2.77 & 7.64 & 8.24 \\
\hline & 8 a 10 & 91.60 & 91.60 & 2.20 & 2.34 & 6.20 & 6.06 \\
\hline & 11 a 14 & 93.95 & 93.29 & 1.64 & 1.98 & 4.41 & 4.73 \\
\hline & Mais de 15 & 95.79 & 96.67 & 0.98 & 1.00 & 3.23 & 2.33 \\
\hline \multirow{6}{*}{ Desempregados $(t)$} & 0 & 34.78 & 19.23 & 34.78 & 34.62 & 30.43 & 46.15 \\
\hline & 1 a 3 & 25.40 & 40.66 & 44.44 & 31.87 & 30.16 & 27.47 \\
\hline & 4 a 7 & 31.01 & 32.62 & 36.18 & 38.33 & 32.82 & 29.05 \\
\hline & 8 a 10 & 24.31 & 30.68 & 51.38 & 41.43 & 24.31 & 27.89 \\
\hline & 11 a 14 & 26.18 & 19.86 & 49.82 & 49.66 & 24.00 & 30.47 \\
\hline & Mais de 15 & 31.11 & 24.14 & 46.67 & 53.45 & 22.22 & 22.41 \\
\hline \multirow{6}{*}{ Inativos $(t)$} & 0 & 5.48 & 6.00 & 0.65 & 0.66 & 93.87 & 93.34 \\
\hline & 1 a 3 & 8.97 & 7.76 & 1.53 & 1.58 & 89.50 & 90.67 \\
\hline & 4 a 7 & 8.78 & 9.58 & 2.76 & 3.36 & 88.46 & 87.06 \\
\hline & 8 a 10 & 10.18 & 10.20 & 6.05 & 6.20 & 83.77 & 83.60 \\
\hline & 11 a 14 & 8.62 & 9.19 & 4.74 & 7.90 & 86.65 & 82.91 \\
\hline & Mais de 15 & 9.94 & 10.99 & 4.42 & 3.66 & 85.64 & 85.35 \\
\hline
\end{tabular}

Fonte: Elaboração própria com base nos microdados da PME de 1997, 1998, 1999 e 2000. 
A fração de tempo na condição de ocupado é crescente com os anos de estudo, ao passo que a parcela de tempo na inatividade decresce à medida que os anos de estudo aumentam. A permanência no estado de desemprego também revela relação crescente com o nível de escolaridade na região metropolitana, com exceção apenas para os indivíduos que possuem pelo menos nível superior completo (mais de 15 anos de estudo), que tendem a permanecer por um período curto nesse estado. A taxa de desemprego desses indivíduos figura, assim, como a de menor magnitude. As taxas relativas dos demais grupos considerados aumentam conforme os anos de estudo. É importante ressaltar a pequena variação entre as taxas de desemprego calculadas e efetivas, gerando, assim, resultados não enviesados (Tabela 6).

Em face do exposto acima, observa-se a importância dos anos de estudo na determinação das taxas de desemprego, bem como na parcela de tempo em cada estado do mercado de trabalho, em que maior grau de escolaridade tende a aumentar a permanência na ocupação e no estado de desemprego.

Tabela 6_Fração de tempo em cada estado do mercado de trabalho e taxas de desemprego, calculada e efetiva, segundo grupos de anos de estudo, para a RMBH, no período de 1999/2000

\begin{tabular}{l|c|c|c|c|c}
\multirow{2}{*}{ Categoria } & \multicolumn{3}{|c}{ Fração de Tempo (\%) } & \multicolumn{2}{c}{ Taxa de Desemprego } \\
\cline { 2 - 6 } & Ocupação & Desemprego & Inatividade & Calculada & Efetiva \\
\hline 0 anos de estudo & 28,16 & 1,99 & 69,84 & 6,61 & 6,37 \\
\hline 1 a 3 anos de estudo & 41,23 & 3,20 & 55,57 & 7,20 & 7,30 \\
\hline 4 a 7 anos de estudo & 51,44 & 4,67 & 43,89 & 8,32 & 8,02 \\
\hline 8 a 10 anos de estudo & 61,35 & 5,92 & 32,73 & 8,79 & 8,85 \\
\hline 11 a 14 anos de estudo & 62,57 & 7,19 & 30,24 & 10,31 & 9,85 \\
\hline Mais de 15 anos de estudo & 79,57 & 3,07 & 17,36 & 3,72 & 3,78 \\
\hline
\end{tabular}

Fonte: Elaboração própria com base nos microdados da PME de 1999 e 2000. 


\section{2_ Duração do desemprego}

A duração média estimada do período completo de desemprego na RMBH, no período de 1997/2001, é de 3,69 meses, tendo em vista o modelo não-paramétrico de Kaplan Meyer. Penido e Machado (2003b) encontraram uma duração de aproximadamente sete meses para essa região, no ano de 1999. Provavelmente, a diferença da duração pode ser atribuída à crise da economia brasileira nesse ano, marcada pela crise cambial com conseqüente mudança no regime e efeitos deletérios sobre o nível de atividade econômica. Por outro lado, o período trabalhado neste estudo é mais abrangente, o que suaviza os efeitos de crise ou a expansão econômica.

Ao se considerar os modelos paramétricos, deve-se procurar a melhor distribuição de probabilidade para descrever a variável duração do desemprego, visto que, se a distribuição não for adequada, os resultados ficarão comprometidos. Na busca da melhor distribuição para descrever a variável duração do desemprego, dois métodos foram considerados: um método gráfico e o teste da razão de verossimilhança. Esses métodos são apresentados a seguir.
Primeiramente, para testar a adequação da distribuição de Weibull e exponencial ao modelo, plota-se o gráfico de $\log \{-\log [S(t)]\}$ contra $\ln (t)$, em que $S(t)$ é a função de sobrevivência obtida pelo estimador de Kaplan-Meier. De acordo com Colosimo (2001), a distribuição de Weibull é a mais adequada se o gráfico obtido for aproximadamente linear. Se, além de linear, o gráfico passar pela origem e apresentar inclinação igual a um, a melhor adequação é dada pela distribuição exponencial (Gráfico 2).

O gráfico acompanha o formato de uma reta, não apresentando nenhum desvio muito significativo. Entretanto, as duas outras condições não são atendidas, a saber: reta com inclinação unitária e que passa pela origem.

Buscando verificar a acuidade da análise gráfica, efetua-se o teste de máxima verossimilhança. Para tal procedimento, realiza-se a seleção das variáveis relevantes do modelo, uma vez que o ajuste de todos esses modelos não se tornaria factível para a seleção do melhor deles, visto que a combinação das doze variáveis consideradas gera 4.096 possíveis modelos para descrever a probabilidade de sair do estado do desemprego. 
11 A metodologia utilizada na seleção do modelo é retratada em Colosimo (2001), e as variáveis de referência são: homens, chefes de família, com idade entre 31 e 50 anos, primeiro grau incompleto, trabalho anterior na indústria, empregado com carteira na ocupação anterior, demitidos da última ocupação, menos de um ano de não-trabalho, com permanência no último emprego de um a três anos, consulta a empregadores como providência tomada para obter uma ocupação e biênio 2000/2001.

\section{Gráfico 2_ Teste de adequação}

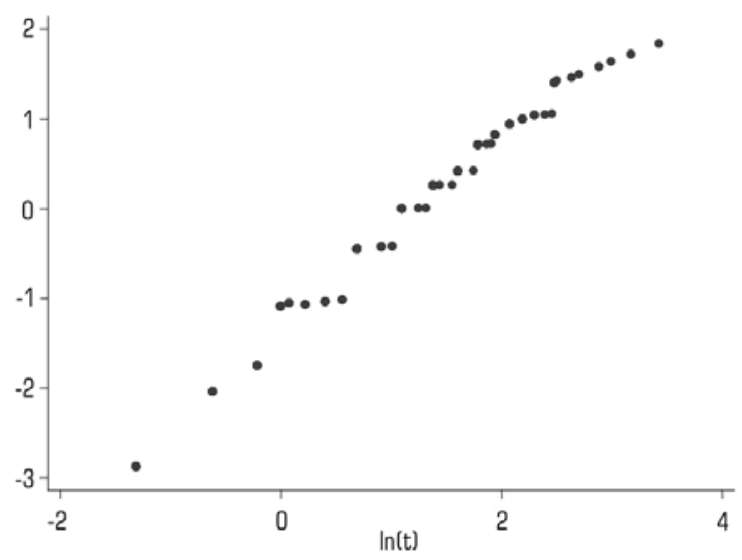

Fonte: Elaboração própria com base nos microdados PME de 1997, 1998, 1999, 2000 e 2001.

Assim sendo, foi feita a seleção das variáveis relevantes para o modelo, ${ }^{11}$ assumindo a distribuição gamma generalizada para o tempo de sobrevivência no desemprego, porque tal distribuição é um modelo geral, em que as distribuições exponenciais, Weibull e log-norma, são casos particulares desta. A melhor especificação é descrita a seguir:

_ Modelo Final $=0$ a 3 anos de estudo +8 a 10 anos de estudo +11 a 14 anos de estudo +15 anos ou mais de estudo + empregado sem carteira na ocupação anterior + empregador ou conta própria na ocupação anterior + pediu para sair da última ocupação + mais de um ano sem trabalho + biênio
+ tempo de não trabalho* segundo grau incompleto + motivo de saída* superior completo ou mais + tempo de não trabalho* conta própria ou empregador na ocupação anterior.

Tendo-se por referência esse modelo, procede-se, então, o teste de máxima verossimilhança. Este é realizado mediante testes de hipótese, em que a hipótese a ser testada é a adequação do modelo. A distribuição gamma generalizada é a utilizada como modelo geral a ser comparado com as demais distribuições. O melhor deles é aquele que mais se aproxima do valor da máxima verossimilhança do modelo com distribuição gamma generalizado. 
Conforme a Tabela 7, percebe-se que a distribuição de Weibull é a que apresenta a melhor adequação. Esse resultado confirma as conclusões obtidas por meio da análise gráfica. Dessa forma, o modelo com distribuição de Weibull para o tempo de sobrevivência no estado de desemprego é aquele considerado na análise. ${ }^{12}$

O modelo paramétrico com distribuição de Weibull para a variável tempo de sobrevivência no desemprego foi estimado, e os resultados podem ser observados a seguir (Tabela 8).

A interpretação da razão de risco depende do fator encontrado ser maior ou menor do que um. Se a razão for maior do que um, a probabilidade de o grupo considerado encontrar uma ocupação é maior do que para os demais, ou seja, esses indivíduos apresentam maior risco com relação aos outros.
Diante dos resultados encontrados, constatam-se riscos menores para os indivíduos mais escolarizados, comparados àqueles com primeiro grau incompleto. Cabe lembrar que, embora o tempo de sobrevivência no desemprego seja maior para os mais escolarizados, uma vez obtida uma ocupação, esses tendem a permanecer mais tempo nela do que os menos escolarizados, como observado na seção anterior. No que concerne ao período de não-trabalho, os indivíduos sem trabalho há mais de um ano apresentam menor probabilidade de sair do estado de desemprego e encontrar uma ocupação em relação àqueles que se encontram nesse estado há menos de um ano. Tal fato é esperado, como lembra Pissarides (1992), uma vez que, estando há muito tempo sem trabalho, os indivíduos tendem a ficar estigmatizados e haverá tendência de deterioração de suas habilidades.

Tabela 7_ Teste de Verossimilhança

\begin{tabular}{|c|c|c|c|}
\hline Distribuição & (-)2LogL & Estatística & Significância \\
\hline Gamma & 2019,3834 & - & \\
\hline Weibull & 2020,0354 & 0,652 & * \\
\hline Exponencial & 2085,9302 & 66,5468 & \\
\hline Log-normal & 2078,3816 & 58,9982 & \\
\hline
\end{tabular}

Fonte: Elaboração própria com base nos microdados PME de 1997, 1998, 1999, 2000 e 2001.
12 Foi realizado o teste de Cox para os resíduos, e esse mostrou que o modelo se ajusta bem aos dados, confirmando, assim, a adequação do modelo escolhido. 
Tabela 8_ Estimativa das razões de risco para variáveis selecionadas, RMBH, 1997/2001

\begin{tabular}{|c|c|c|c|}
\hline Variável & Categoria & Razão de risco & Desvio-Padrão \\
\hline \multirow{4}{*}{ Anos de estudo } & 0 a 3 & 1,008442 & 0,144696 \\
\hline & 8 a 10 & $0,692400^{*}$ & 0,080870 \\
\hline & 11 a 14 & $0,805658^{* *}$ & 0,074515 \\
\hline & 15 anos ou mais & $0,596341 *$ & 0,119739 \\
\hline \multirow{2}{*}{ Posição na ocupação anterior } & Empregado sem carteira & $1,220409 * *$ & 0,102315 \\
\hline & Conta própria ou empregador & $1,317732 * * *$ & 0,221633 \\
\hline $\begin{array}{l}\text { Motivo de saída da última } \\
\text { ocupação }\end{array}$ & Pediu para sair & 1,089700 & 0,111267 \\
\hline Tempo de não-trabalho & Mais de um ano & $0,360299 *$ & 0,039365 \\
\hline Biênio & 1998/1999 & $0,865489 * *$ & 0,064890 \\
\hline \multirow{3}{*}{ Termo de interação } & $\begin{array}{l}\text { Tempo de não-trabalho* } \\
\text { segundo grau incompleto }\end{array}$ & $1,710585^{* *}$ & 0,377582 \\
\hline & $\begin{array}{l}\text { Motivo de saída* } \\
\text { superior completo ou mais }\end{array}$ & $2,105403^{* *}$ & 0,729542 \\
\hline & $\begin{array}{l}\text { Tempo de não-trabalho* } \\
\text { Conta própria ou empregador }\end{array}$ & $0,608752^{* * *}$ & 0,168559 \\
\hline $\begin{array}{l}(*) \text { significante ao nível de } 1 \% \\
(* *) \text { significante ao nível de } 5 \% \text {; } \\
(* * *) \text { significante ao nível de } 10 \%\end{array}$ & & & \\
\hline
\end{tabular}

Constata-se, ainda, considerando a posição ocupada no trabalho anterior, que as pessoas que trabalharam sem carteira assinada apresentam maior probabilidade de encontrar uma ocupação do que aquelas que, na última ocupação, tinham posse de carteira assinada. Isso se caracteriza, sobretudo, pelo fato de essas não receberem indenizações, quando demitidas, e de não serem elegíveis para o seguro desemprego. Os que trabalharam por conta própria ou como empregadores no trabalho anterior apresentam também menor tempo de desemprego relativo àqueles que tinham carteira assinada. $\mathrm{O}$ risco de encontrar uma ocupação para esses indivíduos é 1,32 vezes maior do que para aqueles com carteira na última ocupação. 
Tal resultado também é obtido nos achados das matrizes de transição e por alguns autores como Menezes-Filho e Picchetti (2000 e 2002) e Avelino (2001).

Outro importante resultado é o fato de o tempo de desemprego dos indivíduos ser afetado pela variável biênio. Essa reflete efeitos de período que indiretamente captam o comportamento macroeconômico da região metropolitana. Esse resultado confirma o predito pelo modelo teórico de busca de emprego, que mostra que a obtenção de um posto de trabalho é afetada tanto pelos fatores individuais como pelo comportamento da atividade econômica. Pode ser verificado, para a RMBH, no biênio 1998/ 1999, menor probabilidade de o indivíduo obter uma ocupação do que no biênio 2000/2001. No biênio 1998/1999, reflexos de crises financeiras internacionais com propagação para a economia brasileira, refletiram-se no comportamento do produto, tendo posteriormente (2000/ 2001) voltado a crescer.

\section{6_Considerações finais}

Os resultados deste artigo mostram que o comportamento do desemprego na RMBH é afetado não só pelas características individuais, como também pelo comportamento da atividade econômica, confirmando, assim, o predito pelos mo- delos de busca de emprego. Concernente às características individuais, percebe-se que alguns grupos são atingidos principalmente pelo tempo de permanência no desemprego, enquanto outros apresentam maior incidência nesse estado.

Entre as características do indivíduo, os resultados apontam que o comportamento do desemprego para jovens e mulheres é afetado muito mais pela maior incidência desses grupos no estado de desemprego, em que é observado intensidade e freqüência dos fluxos entre os estados de ocupação, desemprego e inatividade maior, do que um longo período de permanência no estado de desemprego, como é o caso daqueles que possuem maior instrução, indivíduos que estão há mais tempo sem trabalho e que, na última ocupação, tinham carteira de trabalho assinada. Merece destaque os jovens e aqueles que se encontram há mais tempo desempregados, visto que são esses os grupos, respectivamente, que apresentam maior incidência no desemprego e menor probabilidade de saída desse estado para a obtenção de uma ocupação.

Percebe-se que a seletividade do mercado de trabalho, as formas precárias de inserção e o comportamento da atividade econômica dessa região contribuem tanto para o aumento do desemprego quanto para o da rotatividade entre os grupos com menor estabilidade no mercado de trabalho. 


\section{Referências bibliográficas}

AVELINO, Ricardo Rezende Gomes. Os determinantes da duração do desemprego em São Paulo. São Paulo: USP/IPE, 2001. 52 p. (Texto para discussão, n. 11). BIVAR, Wasmália Socorro Barata. Aspectos da estrutura do desemprego no Brasil: composição por sexo e duração. Rio de Janeiro: BNDES, 1993. 101 p. (17 $7^{\circ}$ Prêmio BNDES de Economia, 1993; Originalmente apresentada como Dissertação de Mestrado - Pontifícia Universidade Católica do Rio de Janeiro, 1991).

BLANCHARD, Olivier Jean; DIAMOND, Peter. Ranking, unemployment duration and wages. Review of Economic Studies, v. 61 , n. 208 , p. 417-434, July1994

CHUANG, Hwei-Lin. Estimating the determinants of the unemployment duration for college graduates in Taiwan. Applied Economics Letters, London, v. 6 , n. 10 , p. 677-681, Oct. 1999

CLARK, Kim B.; SUMMERS, Lawrence H. Labor market dynamics and unemployment: a reconsideration. In: SUMMERS, L. H. Understanding unemployment. Cambridge, Mass, MIT, 1990a. p. 3-47.
CLARK, Kim B.; SUMMERS, Lawrence $\mathrm{H}$. The dynamics of youth unemployment. In: SUMMERS, L. H. Understanding unemployment. Cambridge, Mass. MIT, 1990b. p. 48-85.

CLARK, Kim B.; SUMMERS,

Lawrence H. Unemployment

insurance and labor market transitions. In: SUMMERS, L. H.

Understanding unemployment.

Cambridge, Mass, MIT, 1990c.

p. 187-226.

COLOSIMO, Enrico Antônio. Análise de sobrevivência aplicada.

Curso ministrado na Reunião

Anual da Região Brasileira da

Sociedade Internacional de

Biometria, n. 46, e Simpósio de

Estatística Aplicada à

Experimentação, n. 9.

Piracicaba/SP, 2001

FLORI, Priscilla M. Desemprego de jovens: um estudo sobre a dinâmica do mercado de trabalho juvenil brasileiro. 2003. Dissertação (Mestrado) - Faculdade de Economia, Administração e Contabilidade, Universidade de São Paulo, São Paulo, 2003.
FOLEY, Mark. Determinants of unemployment duration in Russia. New Haven, 1997. Disponível em: <http://www.library.yale. edu/socsci/egcdp779.pdf $>$. Acesso em: 17 abr. 2004

GALIANI, Sebástian; HOPENHAYN, Hugo A. Duration and risk of unemployment in Argentina. Buenos Aires: Instituto Torcuato Di tella, 2000. (Working paper)

IBGE. Série histórica da pesquisa mensal de emprego. Disponível em: $<$ http://www.ibge.gov.br>.

LANCASTER, Tony.

Econometric methods for the duration of unemployment. Econometrica, v. 27, n. 4, p. 939-956, July1979.

LAYARD, Richard; NICKELL, Stephen; ACKMAN, Richard.

Unemployment macroeconomic performance and the labour market. Oxford: Oxford University, 1991 Cap. 5. Job Search: the duration of unemployment. p. 216-284.
LEMOS, Mauro Borges. Belo Horizonte no século XXI: documento de referência, relatório síntese. (Projeto de pesquisa Belo Horizonte no século XXI, coordenação geral de: Mauro Borges Lemos, Clélio Campolina Diniz, José Alberto Magno de Carvalho, Fabiana Santos. Belo Horizonte: CEDEPLAR, 2004) Disponível em: <http://www.cedeplar. ufmg. br/pesquisas/sub_pes_pbh.php>.

MALBOUISSON, Cláudia Sá; MENEZES, Antonio Wilson F. Duração do desemprego na Região Metropolitana de Salvador: mensuração e análise. In: ENCONTRO NACIONAL DE ECONOMIA, 32, 2004, João Pessoa, PB. Anais... Belo Horizonte: ANPEC, 2004 Disponível em CD-ROM.

MENEZES-FILHO, Naércio A. PICCHETTI, Paulo. Os determinantes da duração do desemprego em São Paulo. Pesquisa e Planejamento Econômico, Rio de Janeiro, v. 30, n. 1, p. 23-47, abr. 2000. 
MENEZES-FILHO, Naércio A.; PICCHETTI, Paulo.

Os determinantes da duração do desemprego no Brasil metropolitano: 1984-1998.

In: CHAHAD, J. P. Z. MENEZES-FILHO, N. A. (Orgs.). Mercado de trabalho no Brasil: salário, emprego e desemprego numa era de grandes mudanças. São Paulo: LTr, 2002. p. 55-79.

MONTGOMERY, James D.

Social networks and labor-market outcomes: toward an economic analysis. American Economic Review, v. 81, n. 5, p. 1408-1418, Dec. 1991

NICKELL, Stephen. Estimating the probability of leaving unemployment. Econometrica, v. 47, n. 5, p. 1249-1266, Sept. 1979.

OLIVEIRA, Ana Maria Hermeto Camilo de. Acumulando informações e estudando mudancas ao longo do tempo: análises longitudinais do mercado de trabalho brasileiro. 2002. $138 \mathrm{f}$ Tese (Doutorado em Demografia) - Centro de Desenvolvimento e Planejamento Regional, Universidade Federal de Minas Gerais, Belo Horizonte, 2002.

PENIDO, Mariângela; MACHADO, Ana Flávia. Duração do desemprego no Brasil metropolitano. In: WAJNMAN, Simone; MACHADO, Ana Flávia (Orgs.). Mercado de trabalbo: uma análise a partir das pesquisas domiciliares no Brasil. Belo Horizonte: UFMG, 2003a. v. 1, p. 203-218.
PENIDO, Mariângela; MACHADO, Ana Flávia. Duração do desemprego na Região Metropolitana de Belo Horizonte. In: MENDONÇA, Jupira Gomes de; GODINHO, Maria Helena de Lacerda (Orgs.). População, espaço e gestão na metrópole: novas configurações, velhas desigualdades. Belo Horizonte: PUC Minas, 2003b, v. 1, p. 86-108. PISSARIDES, Christopher A. Loss of skill during unemployment and the persistence of employment shocks. Quarterly Journal of Economics, London, v. 107, n. 4, p. 1371-1391, Nov. 1992.

ROED, Knut; RAAUM, Oddbjorn; GOLDSTEIN, Harald. Does unemployment cause unemployment? Micro evidence from Norway. Applied Economics, London, v. 31, n. 10, p. 1207-1218, Oct. 1999.

SIMÕES, Rodrigo Ferreira (Coord.) et al. Servicicos e a Rede Urbana Metropolitana, módulo 4. (Projeto de pesquisa Belo Horizonte no século XXI, coordenação geral de: Mauro Borges Lemos, Clélio Campolina Diniz, José Alberto Magno de Carvalho, Fabiana Santos. Belo Horizonte: CEDEPLAR, 2004). Disponível em: <http://www. cedeplar.ufmg.br/pesquisas/sub_ pes_pbh.php>.
WEBER, Andréa; HOFER,

Helmert. Are job search programs a promising tool? A microeconometric evaluation for Austria. Bonn,

Germany: Institute for the Study of Labor, 2004. (IZA Discussion Paper; 1075).

$\ldots \ldots \ldots$

- E-mail de contato da autora:

: afmachad@cedeplar.ufmg.br

•maantigo@cedeplar.ufmg.br

Artigo recebido em agosto de 2005; aprova-

do em agosto de 2006.

" 